suggestions for improvements, and provision of the famous preface with its brilliant exposition of the Newtonian philosophy of science including Newton's very subtle attitude to gravitational attraction. Sad to say, as Professor Cohen admits, there is no trace in the Newton-Cotes correspondence of any word of thanks from Newton to Cotes for all his enormous labours : and Newton's famous epitaph to Cotes following his early death in 1716: "If Mr Cotes had lived we might have known something" seems to imply that Newton never fully appreciated Cotes' contribution, since but for Cotes the second edition of the Principia, if it had ever appeared, would certainly have been a much less important edition than it actually was.

Throughout almost the whole of the introduction Cohen shows an easy mastery of a vast mass of source material, follows the good example of Newton himself in the matter of English prose style, and strikes a happy balance between an uncritical reproduction of every scrap of relevant information and a too shallow and superficial treatment. Only in chapter 3-"Steps toward the Principia"-does he seem to falter a little. One reason for this may have been uncertainty what to say here about the technical, dynamical aspects of the early steps in the composition of the Principia, about which an additional volume of commentary is promised. In fact the treatment given is not only confused on occasion, especially in the discussion of the various versions of the tract de Motu, but it also contains a number of somewhat hasty judgments which will hardly command universal assent.

Thus it seems to me somewhat improbable that in 1684 Newton was admired by the cognoscenti not only for his discoveries in mathematics but also for his "grasp of the fundamentals of dynamics" (page 47); in the first place Newton was very secretive about his early work in the subject, and in the second place "the fundamentals of dynamics" had, in part, still to be formulated. Equally suspect is the assertion (page 52) that Newton "apparently learnt of Kepler's law of areas in 1678 and at once was able to solve the problem of Keplerian planetary motion" (my italics). This view, originally put forward by D. T. Whiteside ${ }^{1}$, was very improbable $a$ priori, and was then effectively ruled out by J. L. Russell's ${ }^{2}$ demonstration that Kepler's laws had been much more familiar to astronomers in the first half of the seventeenth century than had previously been thought to be the case-Russell lists four authors, Herigone, Ricciolli, Boullian and Wallis, who all cited Kepler's second law in its exact, areal form before 1660. Admittedly, the second law was evidently the least familiar, and its dynamical significance remained entirely hidden before 1679. But it is stretching credulity to suppose that Newton had not noticed-and deeply pondered on-this extraordinary law before 1679. Curious, too, is the assertion (page 53) that "only near or at the surface of the Earth did he (Galileo) conceive of a true linear inertial motion" or the truly extraordinary remarks (page 61) that the tract de Motu "does not yet bear the mark of genius" and contains "no hint of the grandeur of the Principia to come": after all, it was in this tract that Newton first solved the problem of Kepler motion, the very cornerstone of the whole Principia.

Critics will inevitably differ, as critics do, on these and other minutiae. All will be agreed, however, on the magnitude of the achievement of the variorum edition and its introductory volume. Barring the unlikely appearance of important new Newton manuscripts, the whole work will surely remain definitive well into the next century, if not beyond. Alexandre Koyré, I. B. Cohen and their band of devoted assistants have deserved well of the republic of letters, and I can only regret that Koyré did not live to see the completion of the work originally conceived by him and Cohen in 1956 . J. W. HERIVEL

1 Whiteside, D. T., Br. J. Hist. Sci., 2, 117137 (1964)

2 Russell, J. L., Br. J. Hist. Sci., 2, 1-24 (1964).

\section{Rockets and roubles}

The Origins and International Economics of Space Exploration. By Bernard Lovell. Pp. viii + 104. (Edinburgh University: Edinburgh, 1973.) $£ 1.50$.

IT is excellent to find such a wealth of information in so slim a volume. I especially enjoyed the succinct and clear historical part (the first quarter of the book). To describe the early military history of the rocket, to disentangle the labours of Tsiolkowsky, Goddard and Oberth, to demonstrate the independence of Soviet work from the earlier German efforts, to explain the administrative tangles in the United States before NASA got going, and all in some twenty very readable pages is most valuable. Much of the rest of the book gives data on costs and on numbers of launchings, and examines the relative sizes of civil and military space efforts in both United States and Soviet Union all in very convenient and easily assimilable form, and describes briefly, and perhaps a bit conventionally, the various benefits of space activity. Science in particular is dealt with too briefly for anybody to learn much from it, but more justice is done to the applications. The contrast of the cost of manned and unmanned space activities is well brought out, and a somewhat implicit admiration, richly deserved, for the political vision, superb decision taking, and technological brilliance of the Apollo programme is understandably followed by a much more dubious attitude to later manned activities (Skylab and Shuttle) to which so much highly promising space science (high energy astronomy and planetary observation) is being sacrificed.

However much I admire these concise descriptions, I am distinctly less thrilled by Sir Bernard Lovell's more philosophical comments, comments that are far too brief and therefore lack clarity and depth. If there was not the room to develop the argument more fully (which might well have been fascinating), then the commentary should have been left out. As it is, the reader is simply confused and irritated by the sputtering that first points one way, then the other, never addressing itself to any problem for long enough, never resolving the contradictions.

To give some examples: after soberly describing the V1 and V2 campaigns, and the casualties caused, he rightly says that these weapons could have affected the war far more but for the bombing of Peenemunde, only to be "filled with dismay and an unresolved conflict" by the thought that this bombing was made possible by the blind bombing aid which he had helped to develop "illuminating for destruction the genesis of one of the greatest scientific developments of all time ....". His dismay is hard to understand, given the facts of the situation. Similarly, on page 86 he stresses that the United Kingdom's space expenditure was so minute that, if transferred to education, health and social security, it would have hardly made any difference, but on page 87 he speaks of wasting "these extremely large sums" (that is, those applied to space, perhaps including this time the other European countries). Whether depending on the United States for launching rockets (page 87) is the bad thing it is implied to be at least deserves to be debated. I, too, am keen on space, but would find it hard to sustain (though I would enjoy reading a good argument on the issue) the assertion that "many of the urgent problems associated with the predicted doubling of the world's population can be alleviated by space applications" (page 88). These are important and controversial issues on which reasoned argument would have been most welcome, but little benefit is derived from over-brief and often unclear assertions.

But my gripe about what is not in the book should not cloud my advice to all interested in space to read it for its factual content.

H. BONDI 